\title{
Artigos
}

\section{Encontros e desencontros entre projetos pedagógicos de cursos de Medicina e Diretrizes Curriculares Nacionais: percepções de professores}

Convergence and gaps between medical courses educational projects and the National Curriculum Guidelines: university professors' perceptions (abstract: p. 15)

Encuentros y desencuentros entre proyectos pedagógicos de cursos de Medicina y Directrices Curriculares Nacionales: percepciones de profesores (resumen: p. 15)

Carlos Alberto de Oliveira ${ }^{(a)}$

<cadoliveira@pucsp.br> iD

Eliana Martorano Amaral ${ }^{(\mathfrak{b})}$

<elianaa@unicamp.br>

Eliana Goldfarb Cyrino(c)

<eliana.goldfarb@unesp.br> (iD

Reinaldo José Gianini(d)

<rgianini@pucsp.br>

\author{
(a, d) Departamento de Saúde \\ Coletiva, Faculdade de \\ Ciências Médicas e da Saúde, \\ Pontifícia Universidade \\ Católica de São Paulo. Joubert \\ Wey, 290, Vila Boa Vista. \\ Sorocaba, SP, Brasil. \\ 18030-070. \\ (b) Departamento de \\ Tocoginecologia, Faculdade de \\ Ciências Médicas, Universidade \\ Estadual de Campinas. \\ Campinas, SP, Brasil. \\ (c) Departamento de Saúde \\ Pública, Faculdade de \\ Medicina de Botucatu, \\ Universidade Estadual Paulista \\ "Julio de Mesquita Filho". \\ Botucatu, SP, Brasil.
}

Compreender a consolidação das Diretrizes Curriculares Nacionais (DCN) demanda contextualizar a realidade de cada instituição. Sua implantação pressupõe (re) orientação do processo de formação na Saúde, com integração entre Projeto Pedagógico do Curso (PPC), Sistema Único de Saúde (SUS) e envolvimento docente. Para captar a percepção docente sobre o alinhamento entre PPC e DCN, realizou-se estudo exploratório com metodologia qualitativa e os docentes respondendo a um questionário. Utilizou-se análise de conteúdo para construção de categorias temáticas. Os docentes de uma escola reconhecem que o PPC não está alinhado às DCN. Revelam trabalho docente determinado por perfil profissional e pessoal. Em outra escola, cuja reforma curricular já adota metodologia de ensino-aprendizagem ativa, os docentes se sentem apropriados às DCN. Concluímos, portanto, que as mudanças no PPC são processos que demandam tempo, dedicação e comunicação, ou seja, maior mudança na instituição de ensino.

Palavras-chave: Educação médica. Integração ensino-serviço. Diretrizes para o planejamento em saúde.

Oliveira CA, Amaral EM, Cyrino EG, Gianini RJ. Encontros e desencontros entre projetos pedagógicos de cursos de Medicina e diretrizes curriculares nacionais: percepções de professores. Interface (Botucatu). 2021; 25: e200076 https://doi.org/10.1590/interface.200076 


\section{Introdução}

Em todo o mundo, os sistemas públicos de saúde têm passado por profundas transformaçốes, consequentes a mudanças demográficas, epidemiológicas, sociais, econômicas e políticas. Em que pese um enorme esforço em diversas regiôes do mundo em busca de implantar, desenvolver e qualificar sistemas públicos de saúde que melhor respondam às necessidades de saúde das populações, nos últimos quarenta anos, os modelos de formação nas graduações médicas não acompanharam essas mudanças. No Brasil, as mudanças recomendadas pelas Diretrizes Curriculares Nacionais (DCN) do curso de graduação em Medicina de $2001^{1}$ e ratificadas pelas DCN de $2014^{2}$ ainda encontram resistências e dificuldades à plena implementação. Muitas instituiçốes estão arraigadas em uma estrutura de disciplinas e departamentos isolados e pouco integrados, com desenho tradicional de ensino médico, tendo como base o relatório Flexner do início do século $20^{3-5}$.

As dificuldades observadas referem-se à lacuna na adoção de novas estratégias educacionais, à necessária integração curricular com o Sistema Único de Saúde (SUS) ${ }^{6-8}$ à falta de atuação e centralidade na Atenção Primária à Saúde (APS), à ausência de formação interdisciplinar e interprofissional e à carência de alinhamento de objetivos e açôes entre docentes, coordenadores de curso e gestores do SUS, questóes presentes nas DCN 2001 e 2014.

Para compreender o alcance das DCN no ensino superior em Saúde é preciso contextualizar a realidade do ensino nas Instituiçóes de Ensino Superior (IES), do processo de desenvolvimento profissional para o exercício da docência e, principalmente, do conhecimento e da prática pedagógica e profissional desses sujeitos em relação à apropriação do Projeto Pedagógico do Curso de Medicina (PPC). Como ensina Paulo Freire?:

[...] para ter força de mudança é necessário ao processo educativo estabelecer relação de organicidade com a contextura da sociedade a que se aplica (Educação e atualidade brasileira. 2002, p. 10)

Considerando a importância e a relevância que os PPC dos cursos de Medicina devem desempenhar na facilitação da aprendizagem para a consolidação das $\mathrm{DCN}^{10}$, no sentido de promover uma (re) orientação em todo o processo de formação em Saúde, torna-se necessário compreender a percepção de docentes sobre esse alinhamento (PPC e DCN). $\mathrm{Na}$ busca de entender seus aspectos mais relevantes, propusemos o presente estudo. 


\section{Métodos}

Trata-se de pesquisa exploratória, com metodologia qualitativa, que teve como universo de estudo docentes de escolas médicas contemporâneas estabelecidas a partir da segunda metade do século 20, sendo uma delas a autarquia municipal (IES1) e a outra, confessional filantrópica (IES2). Foram realizadas entrevistas com base em roteiro preestabelecido ${ }^{11-14}$. O referencial teórico que alicerçou a análise de conteúdo para apreensão dos dados dos questionários foram os textos de Bardin, Minayo, entre outros. Todo o material coletado desses questionários foi transcrito por profissionais habilitados, organizados em categorias de significação para a posterior interpretação, de acordo com a categorização sugerida. A construção de categorias temáticas foi realizada com o auxílio dessa equipe especializada (empresa ligada a uma universidade) em abordagem de estudos qualitativos, por meio de leitura profunda do material empírico ${ }^{15,16}$ transcrito para se compreender, interpretar, refletir e analisar a realidade que se apresentou em cada escola.

Como características básicas da singularidade de cada uma das escolas estudadas, destacamos que a IES1 oferece cem vagas para o curso de Medicina, currículo seriado por disciplinas com carga horária total de 10.310 horas-aula e internato, com carga horária de 3.600 horas, nos dois anos finais do curso. A IES2 tem o curso de Medicina baseado em um PPC reconhecidamente inovador e centrado em pessoas, com oferta de 130 vagas, carga horária total de 7.920 horas, internato nos três últimos anos do curso, com carga horária de 4.140 horas.

A coleta dos dados com os docentes que aceitaram o convite para participar da pesquisa (convidamos reiteradamente - três convites - todos os docentes que tinham atividades educativas no terceiro e/ou no sexto ano do curso de Medicina das duas instituições de ensino) ocorreu após explicação do pesquisador e assinatura dos termos de consentimento livre e esclarecido. Alguns encontros foram face a face (4), por videoconferência (3), e outros, enviados por e-mail (2). Escolhemos os professores especificamente do terceiro ano e do sexto ano, pelo fato de os primeiros desenvolverem atividades educativas para alunos que estão exatamente no meio do curso de Medicina e, portanto, já estão acostumados com as práticas educativas utilizadas em seu curso. Por outro lado, os docentes do final do curso têm contato com os concluintes do curso que vivenciaram todo o processo com as metodologias educativas recomendadas no seu PPC. Participaram voluntariamente quatro docentes da IES1 e cinco docentes da IES2. Dessa forma, nossa amostragem foi por conveniência e não por saturação. Dois docentes em cada IES davam aulas para turmas de terceiro e sexto anos, dois eram docentes do terceiro ano e um dos docentes da IES2 tinha atividades no sexto ano de internato. Encontrou-se dificuldade na realização do total de entrevistas propostas inicialmente para se trazer à tona maior riqueza de conteúdo e diversidade de percepção, pois foram entrevistados aqueles docentes que se dispuseram a fazê-lo, o que, por si só, poderia representar um viés. No entanto, não podemos afirmar que esse fato, per si, indique uma relação de menor ou maior diversidade de percepçóes.

O estudo foi aprovado pelo Comitê de Ética em Pesquisa (CEP) da IES1 sob o número CAAE 62459816.5.3001.5412 e pelo CEP da IES2 sob o número CAAE 62459816.5.0000.5373, após aprovação nas respectivas coordenaçóes de graduação. 


\section{Resultados e discussão}

O material empírico das observações e experiências relatadas permitiu a construção de quatro categorias temáticas: 1) Estratégias de ensino-aprendizagem; 2) Estratégias de avaliação do estudante; 3) Inserção dos discentes na Atenção Básica à Saúde (ABS) e 4) Alinhamento entre os PPC e as DCN de Medicina de 2001 e 2014.

A análise temática procurou abarcar a realidade multidimensional que extraímos das entrevistas com os docentes.

\section{Categoria 1: transições entre estratégias de ensino-aprendizagem}

Tento estabelecer uma dinâmica mais ativa, com participação dos alunos na dinâmica da atividade. A estrutura me obriga com frequência a oferecer atividades tradicionais com metodologia passiva, infelizmente. (P2 - IES1)

Os professores, na maioria das suas atividades, não seguem as ementas descritas no plano de ensino. Dessa forma, os objetivos de aprendizagem, não raro, são diferentes daqueles propostos inicialmente e que constam nos documentos oficiais. Nos questionários foi possível perceber que há professores ainda resistentes às mudanças propostas, mesmo aquelas que são consideradas como pequenas alteraçôes, seja na metodologia de ensino aprendizagem seja nos procedimentos de avaliação. Alguns deixam claro, em suas falas, que gostariam de trabalhar em instituiçốes que remuneram os professores de forma mais justa.

São inúmeras as estratégias de ensino-aprendizagem que podem ser utilizadas por professores e alunos com o objetivo de os últimos adquirirem informação e construírem conhecimentos. A proposta dessas técnicas é facilitar tanto a aquisição quanto o armazenamento e a utilização das informaçóes e/ou dos conhecimentos apreendidos. Dessa forma, o currículo deveria proporcionar ao professor o uso livre das diversas estratégias, mesclando-as tanto quanto possível. No entanto, o currículo, na maioria das vezes, não proporciona essa liberdade, propondo o uso de técnicas puras, como PBL ou TBL, aulas expositivas ou palestras magistrais etc.

Como desdobramento, percebe-se, nos trabalhos de estudiosos, que os modos convencionais de transferência de conhecimento, mediante métodos de ensinoaprendizagem alicerçados em conteúdos e protocolos para desenvolvimento de competências e habilidades, estão superados ${ }^{17,18}$. Afinal é impossível manter os alunos com a atenção focada por mais de 15 a 20 minutos se não houver uma troca de assuntos. Discute-se que, por isso, a metodologia proposta nos currículos segue o princípio da classificação tecnoburocrática generalista, quando deveria ser qualificada, como método de ensino, em uma perspectiva histórico-dialética ${ }^{19}$.

Nas falas dos professores da IES1, surgiu a

[...] experimentação de outras técnicas ou metodologia de ensino aprendizagem como forma de buscar a articulação das diretrizes curriculares propostas com procedimentos que poderiam desenvolver a aprendizagem de forma ativa. (P1 - IES1) 
Em suas reflexões, os docentes da IES2, uma vez que a metodologia proposta já é apresentada como ativa em seu PPC, sentem maior dificuldade quanto ao uso de outras técnicas didáticas e, portanto, os professores (tutores, orientadores) não deixam claro se utilizam outras estratégias técnico-operacionais para o ensino-aprendizagem.

Embora nosso curso seja metodologia ativa, com exceção das tutorias, acredito que as aulas, como as sustentações teóricas, ainda são as teóricas tradicionais. (P5 - IES2)

Talvez neste momento seja preciso deixar claro que sistemas híbridos de ensinoaprendizagem podem propiciar um melhor desenvolvimento de habilidades e atitudes discentes, haja vista a importância de utilização das diversas metodologias de ensino. Isso ficou claro nas entrevistas, uma vez que os docentes da IES 1, com ensino dito tradicional, reconhecem a necessidade do uso de algumas formas de metodologias ativas, e os docentes da IES2, com uso de metodologias ativas de ensino, também utilizam aulas magistrais ou pequenas palestras. No entanto, é preciso ainda destacar que a literatura mundial sobre o tema não é conclusiva quanto à necessidade de aulas expositivas como complementação de qualquer método de ensino centrado no aluno. O que importa, e muito, é que qualquer atividade educacional, principalmente com adultos, seja discursivo-reflexiva e centrada na pessoa.

\section{Categoria 2: avaliações globais ou pontuais}

Apesar de parecer paradoxal, a avaliação do estudante trouxe consenso às discussóes docentes. Há concordância quanto à complexidade do fenômeno avaliativo e, independentemente de uma análise mais aprofundada das justificativas dessa complexidade, a avaliação se mostra uma categoria especial e árida ${ }^{20}$.

A diversidade dos atores envolvidos torna claros os diferentes valores, os diferentes interesses e até as concepçôes conceituais diversas.

Aplicação de provas com questóes objetivas e dissertativas e entrega de algum trabalho extra. (P3 - IES1)

O projeto define que a avaliação deve ser apropriada às metodologias eleitas no PPC, tanto as somativas como as formativas. Portanto, elas devem ser integradas (não separadas por área de conhecimento) e incluir um rol de instrumentos que correspondam aos desempenhos que se pretende avaliar. (P1 - IES2)

No entanto, sabemos que a avaliação da aprendizagem pode promover avanços tanto na qualificação da escola quanto no desenvolvimento do estudante ${ }^{21}$.

A progressão do aluno, acompanhada pelas avaliaçôes, decorre da capacidade de o professor ter uma visão longitudinal da aprendizagem assimilada pelo aluno, ou seja, consiste em determinar se os objetivos educacionais foram alcançados e quanto de mudança esses saberes proporcionaram às atitudes do aluno. 
A avaliação utilizada pelos docentes da IES1 é exclusivamente cognitiva, de forma que são aplicadas provas escritas para verificar apenas o domínio do conhecimento. Quando são feitas em testes, são de difícil elaboração, limitando-se a uma avaliação rápida e objetiva, e têm feedback quase imediato, mas não avaliam a habilidade de expressão do aluno. Quando feitas com questóes dissertativas, elas se propóem a avaliar o conhecimento, a capacidade reflexiva, a organização das ideias e a expressão do estudante. Demandam mais tempo para sua correção e, consequentemente, of feedback torna-se mais demorado.

Os docentes da IES2 descreveram os diversos tipos de avaliação que utilizam, por exemplo, provas escritas, provas orais, provas práticas, Mini-CEx e provas de estações. A prova oral é uma técnica que facilita ao aluno expor reflexão e crítica. O Mini-CEx, concebido para a avaliação de internos, é uma escala de classificação que avalia seis competências clínicas nucleares ${ }^{22}$. Desenvolvido pela American Board of Internal Medicine (Abim), proporciona uma observação direta, pelo preceptor, do estudante exercendo o atendimento. Já a prova de estações, como o Objective Strutured Clinical Examination (Osce) ou exame clínico objetivo estruturado, avalia o desempenho do estudante em situaçốes delimitadas e roteiros preestabelecidos (checklists) ${ }^{23}$. Pode propor interação com pacientes simulados ou recursos didáticos (forma empregada na IES2), utilizando-se de avaliação em rodízio.

Dissemos, anteriormente, que o tema avaliações trouxe consenso, mas é preciso explanar melhor, pois o consenso é de que a avaliação é uma tarefa difícil e muito necessária. Observamos que os docentes da IES1 reconhecem a necessidade de ampliar as dimensóes avaliadas e alguns, inclusive, já realizam avaliaçóes formativas pontuais associadas com as avaliações cognitivas. Por outro lado, os docentes da IES 2, apesar de realizarem avaliaçóes formativas e somativas, concluem que todo o sistema avaliativo ainda precisa ser melhorado. Talvez a avaliação 360 graus possa trazer esse conforto, visto que se trata de uma avaliação mais global, pois envolve autoavaliação, avaliação por pares, avaliação pelos pacientes e equipe de saúde, ou seja, há feedbacks de todos os envolvidos. Dessa forma, possibilita discussóes dos pontos fortes e fracos no intuito de favorecer melhorias individuais, pois é multiangular (envolve vários atores), além de facilitar a reflexão sobre a práxis.

\section{Categoria 3: a nova fronteira para o ensino-aprendizagem da prática médica}

Se por um lado as instituiçôes de ensino superior com cursos de Medicina precisaram adequar seus projetos pedagógicos acompanhando as transformaçóes da sociedade, e deslocaram o ensino do hospital para a APS, valorizando a prevenção de doenças, a promoção à saúde e o trabalho interdisciplinar; por outro, as DCN (2014) normatizaram as necessidades de os cursos oferecerem estágios obrigatórios no SUS e nos serviços de urgência/emergência, com carga horária correspondente a 30\% do internato.

As reflexóes dos docentes da IES1 deixaram claro que, apesar de reconhecerem que os alunos são obrigados a frequentar os cenários no SUS, não acham isso relevante. Destacam o enorme distanciamento entre a academia e as unidades de $\mathrm{AB}$ do SUS, ressaltando que os médicos que atendem nas unidades de saúde do SUS não são preceptores e, portanto, não ensinam nada. Dessa forma, evidenciam que essa inserção é indesejável e no máximo tolerável. Assinalaram, ainda, que tais falhas na APS são contraproducentes, mas nada disseram sobre o sistema secundário ou terciário da rede SUS. 
Não há essa necessidade, pois a meu ver existem péssimos profissionais nas unidades básicas de saúde, exclusivamente por questóes salariais e culturais. Os médicos das unidades básicas são muito mal remunerados e não possuem recursos estruturais para o exercício da profissão. Além disso o trabalho em unidade básica encontra-se estigmatizado como péssimo serviço assistencial. (P1 - IES1)

Já os docentes da IES2 ressaltaram ser de suma importância que os alunos vivenciem essa realidade de atendimento às pessoas também nos cenários da rede SUS (UBS, Caps, Samu, UPAs, UPHs e hospitais), pois essas possíveis falhas da APS são fontes reais de aprendizado e até motoras de um processo de mudança, sendo ele, o aluno, o coautor. Reconhecem inclusive que a equipe de professores, médicos especialistas em Medicina de Família e Comunidade (MFC), que acompanha e realiza preceptoria aos alunos desde o primeiro ano da graduação em Medicina, é de alto nível e muito bem avaliada pelos alunos, pois é lembrada como composta de profissionais que aliam a ética e a eficácia, praticando uma medicina centrada na pessoa. Deixam claro que são favoráveis, inclusive, ao estágio obrigatório no SUS após a conclusão do curso, previsto em medida provisória governamental, para os estudantes que iniciaram o curso de Medicina em 2015 24,25.

Em nosso curso todos os alunos passam em UBS e ambulatórios; acho fundamental. (P5 - IES2)

\section{Categoria 4: as DCN de Medicina - relativização e prática}

As DCNs são parâmetros norteadores a serem seguidos nacionalmente na elaboração dos projetos pedagógicos dos cursos de graduação e estimulam novos modelos de organização curricular. A organização curricular tradicional é centrada no conteúdo e prioriza aulas expositivas; já a organização curricular integrada propõe uma matriz curricular focalizada nas competências e habilidades adquiridas, priorizando o trabalho integrado, a autonomia intelectual progressiva e o estudo independente ${ }^{26}$.

Entretanto, cabe ressaltar que a Constituição Federal estabelece no seu artigo 207 que "As universidades gozam de autonomia didático-cientifica, administrativa e de gestão financeira e patrimonial [...]", assim a elaboração e/ou a atualização do PPC constitui responsabilidade institucional ${ }^{27,28}$.

Os docentes da IES1 pontuaram que, devido à extensa carga horaria do curso de Medicina (10.310 horas), cerca de 43,2\% acima do mínimo exigido pelo Ministério da Educação (7.200 horas), o PPC da sua instituição está desalinhado com as DCN. Ele apenas satisfaz as exigências legais, pois em sua maioria preserva os interesses pessoais de seus docentes com uma prática médica hospitalocêntrica.

Quanto às diretrizes de 2014, até onde sei, há desalinhamento, pois atualmente há excesso de carga horária na [...] (P1 - IES1) 
Já os docentes da IES2 reconhecem muitos pontos de agregação entre o PPC de sua instituição e as DCN, afinal o curso de Medicina tem seu currículo modular com eixos norteadores, carga horária total ( 7.920 horas) apenas $10 \%$ acima do mínimo exigido e internato na $\mathrm{AB}$ com carga horária acima das exigências da DCN. Dessa forma concluem que o PPC de sua instituição está alinhado com as DCN, não apresentando conflitos com o modelo do SUS, mas reconhecem que é preciso avançar ainda mais na busca desse alinhamento com as normativas.

Com as de 2001, há um alinhamento muito grande, faltando o salto qualitativo para maior efetividade. Com as de 2014, será preciso adequar os aspectos de gestão. (P1 - IES2)

De forma geral, observamos uma proximidade de alinhamento dos PPC com as DCN maior que o esperado, considerando que estávamos contrastando instituições com projetos pedagógicos tão diferentes: uma que adotou as metodologias ativas, com concepção dialógico-reflexiva, centrada nas pessoas com aprendizagem significativa; e outra que embasa o currículo em aulas ou conferências, algumas vezes problematizadas com situações clínicas. As reflexóes manifestadas pelos docentes das duas IES deixam claro que há uma distância ( gap) entre o PPC e as DCN, que pode ter ocorrido pelo distanciamento entre o processo de discussão e revisão curricular e aqueles que o efetivam, sem promover alterações específicas que envolvam extensamente os docentes.

Essa situação reforça o que a literatura recomenda, que é a ampla participação da comunidade nas mudanças de currículo, acompanhada pela preparação do corpo docente para novas metodologias de ensino-aprendizagem sugeridas nas $\mathrm{DCN}^{29-31}$. Destaca-se, também, que a maioria dos docentes desconhece as DCN, tampouco demonstra interesse em conhecê-las. O conhecimento dos arcabouços legais e teóricos que orientam os PPC e devem inspirar as atividades docentes é raro ${ }^{32}$. Entre seus aspectos essenciais está o uso de metodologias ativas, assim como de avaliaçóes de competências para a formação de um médico geral, com perfil humanista, reflexivo, crítico e preparado para atender no SUS ${ }^{1,2}$. Ainda é possível destacar que o cenário de prática baseado no ensino em comunidades (UBS) é um caminho de duas vias: a comunidade beneficia-se da expertise dos professores e da disponibilidade dos estudantes, enquanto o curso de Medicina, como um todo, se beneficia com a aprendizagem que vem da práxis, da observação pessoal e da interação social ${ }^{33}$.

É responsabilidade da IES a seleção e a contratação do docente, o apoio para o seu desenvolvimento e o exercício profissional de forma continuada e, ainda, a supervisão das suas atividades. Os programas de desenvolvimento docente focados em metodologias ativas e integrativas mostraram-se efetivos quando convergiram para os seguintes aspectos: a) investimentos em capacitação, em educação permanente/ continuada, em pós-graduação e em formação gerencial; b) políticas de participação em congressos, seminários, oficinas de atualização, comissóes externas e de política de saúde local; c) plano de incentivo à capacitação docente, em nível de pós-graduação; d) núcleo de apoio pedagógico; e) atuação de profissionais do SUS nas escolas como 
preceptores e de professores das escolas atuando na rede com os discentes; f) sensibilização e instrumentalização do corpo docente para as mudanças; e, por fim, g) capacitação docente permanente e em vários níveis ${ }^{34,35}$. De forma geral, os programas de desenvolvimento docente com impacto positivo e duradouro são aqueles que apresentam um caráter de longo prazo, longitudinal, envolvendo e dando suporte ao planejamento, assim como à implementação ${ }^{36-39}$.

Os questionários dos docentes revelaram que a ação docente é determinada mais pelo seu próprio perfil do que pelo plano de ensino da disciplina ou módulo. Não cabe aqui discutir profundamente a ação do "currículo oculto", no entanto, podemos inferir que "a abordagem a partir do currículo real e da experiência de vida tem consequências enormes quanto ao papel do professor", como nos ensina Perrenoud. Assim, mesmo na IES com metodologia ativa descrita no seu PPC, o professor, não raro, utiliza o recurso das aulas expositivas. O uso de "palestras” em currículos que adotam Problem Based Learning (PBL) - aprendizagem baseada em problemas - já foi relatado na literatura brasileira e internacional ${ }^{32,40,41}$. Dessa forma, a inclusão de conferências magistrais nesses currículos não é nova e pode ter lugar para sintetizar e atualizar temas complexos ${ }^{42,43}$.

Pelas reflexôes docentes, percebe-se que a desvalorização do trabalho médico acaba refletindo na prática do ensino dos futuros médicos. O fato de as UBS não terem estrutura adequada para esse ensino é outro fator negativo que desestimula a adesão pessoal à proposta $^{44}$. Fato que se destaca nos diversos níveis de atenção do ensino médico ${ }^{6,45}$.

É inconteste que mudanças constantes nos currículos das escolas médicas se impóem devido às permanentes mudanças da sociedade, do avanço no conhecimento, da complexidade vivencial e das inovaçốes na educação. Entretanto, é necessário um olhar especial e esforços dedicados a apoiar aqueles que participam dessa mudança.

A transformação curricular, complexa e multifacetada, deve ser uma construção coletiva, articulando e envolvendo os diversos atores e colaboradores da instituição de ensino. Deve abordar mudanças pedagógicas nos cenários de prática e principalmente atividades na ABS. No entanto, é preciso, também, estar atento para a insegurança que gera, assim como para os efeitos negativos no bem-estar e na saúde mental dos estudantes ${ }^{46}$. Desenhos educacionais com o uso de metodologias ativas de ensinoaprendizagem devem prover mecanismos de defesa no sentido de mitigar os efeitos estressores durante e após as mudanças ${ }^{13}$. É preciso acompanhar mais de perto os discentes, mas também os docentes, oferecendo suporte como mentoria e coaching, além de atividades de desenvolvimento docente para o melhor uso das diferentes estratégias.

O questionamento sobre a necessidade ou a oportunidade de ter experiências de formação na APS demonstra a pouca familiaridade do corpo docente das instituiçóes brasileiras com as mais recentes tendências na educação em saúde ${ }^{47-50}$. De fato, a experiência brasileira é ampla em educação médica baseada na comunidade e tem inspirado outros cursos na área da Saúde em diversos países ${ }^{33}$. 


\section{Considerações finais}

Os docentes da IES1 reconhecem mais claramente que o PPC ainda não está alinhado com as DCN de 2014, apesar de explicitarem que muito já foi feito nesse sentido, visto que alguns professores têm tentado utilizar algumas metodologias centradas no aluno. Contudo, é conhecido que qualquer mudança curricular precisa de tempo para ser internalizada. A percepção diferenciada dos docentes quanto ao alinhamento do PPC e as DCN de 2014, nas duas IES, talvez decorra do fato de que a mudança curricular na IES2 ocorreu há mais tempo. Devido a isso, os docentes, agora mais bem capacitados para metodologias ativas de ensino-aprendizagem e para estratégias educacionais de avaliação (globais), compartilham suas práticas nos novos cenários de ensino (UBS). Destarte, percebem com mais clareza tanto as oportunidades como as resistências às mudanças que existem, sendo capazes de refletir no sentido de superá-las.

Ao olhar para o futuro da educação médica, vislumbramos a necessidade de mesclar os elementos dos diversos métodos de ensino-aprendizagem com abordagens baseadas em evidências, a fim de propiciar o desenvolvimento de habilidades de comunicação, o engajamento e a resolução de problemas, alicerçando dinâmicas para o desenvolvimento de trabalhos em equipes multiprofissionais, além de bons desempenhos cognitivos.

Acreditamos que esse é o objetivo proposto nas DCN para os cursos de Medicina; no entanto, seguir essas normativas é um grande desafio; afinal, por trás da racionalidade das IES existem pessoas reais (estudantes, professores, colaboradores e gestores) que dão diferentes significados para as mudanças. Essas percepçóes acabam por trazer à tona algumas resistências no desenrolar desses processos. Como, por exemplo, obstáculos financeiros, administrativos e políticos, que podem impedir ou inviabilizar a concretização dessas mudanças e dos alinhamentos entre os PPC e as DCN.

Por fim, esta análise, mesmo que em pequeno número, mostra a diversidade e a complexidade desses inúmeros obstáculos enfrentados pelas IES, para que os PPC dos cursos de Medicina efetivamente se alinhem às DCN, não apenas “no papel”, mas também na prática diária docente.

Algumas considerações sobre os resultados deste estudo podem ser identificadas como limitadas, por exemplo, a dificuldade de ampliar a amostra docente e desvelar maior riqueza de conteúdo ou diversidade de percepção, pois responderam ao questionário aqueles docentes que se dispuseram a fazê-lo, o que, por si só, poderia representar um viés. Convidamos todos os docentes que tinham atividades no terceiro e/ou no sexto ano da graduação das duas IES, mas não conseguimos realizar o trabalho de campo com todos. Essa baixa adesão se alinha à observação da sobrecarga de atividades dos professores, dos médicos e dos professores/médicos refletida nos questionários.

Ainda assim, o estudo fornece pistas e indagaçóes àqueles que dirigem as iniciativas de mudança curricular nas escolas de Medicina, sejam elas relativas ao planejamento, à implantação e à institucionalização. Os fatores que fortalecem ou enfraquecem os processos de mudança emergiram nas reflexôes dos docentes das duas IES. Também se mostraram como fatores importantes a alocação de recursos, a estrutura organizacional, o clima cooperativo dos docentes, a complexidade da inovação, a capacitação docente 
prévia, a boa comunicação, o entendimento da queda de desempenho nos momentos iniciais da mudança e o reconhecimento das lideranças ${ }^{51-54}$. Este modelo de estudo, assim como outros ${ }^{55}$ que vêm sendo produzidos, pode contribuir para maior compreensão do tamanho da dificuldade de mudar a educação médica em nosso país no sentido de aproximá-la das necessidades de formação do SUS. “O ordenamento da formação de recursos humanos na área da Saúde com vistas a atender às necessidades do SUS continua a ser um desafio atual, sobretudo na área médica" ${ }^{55}$ (p. 10).

\section{Contribuições dos autores}

Carlos Alberto de Oliveira, pesquisador principal, participou dos encontros com os docentes das duas instituições de ensino superior e foi responsável pela preparação, escrita do texto e análises dos dados. Eliana Martorano Amaral contribuiu com a elaboração do projeto e o desenho do estudo, a análise dos dados e a preparação do texto. Eliana Goldfarb Cyrino participou nas revisóes do texto e na preparação do texto final. Reinaldo José Gianini contribuiu na revisão da metodologia, na preparação e na revisão do texto.

\section{Conflito de interesse}

Os autores não têm conflito de interesse a declarar.

\section{Direitos autorais}

Este artigo está licenciado sob a Licença Internacional Creative Commons 4.0, tipo BY (https://creativecommons.org/licenses/by/4.0/deed.pt_BR).

\section{(cc) BY}

\section{Editor}

Vera Lucia Garcia

Editor associado

Lilian Koifman

\section{Submetido em}

27/02/20.

Aprovado em

$11 / 10 / 20$. 


\section{Referências}

1. Brasil. Ministério da Educação. Conselho Nacional de Educação Câmara de Educação Superior. Resolução CNE/CES no 3, de 20 de Junho de 2014. Institui Diretrizes Curriculares Nacionais do Curso de Graduação em Medicina e dá outras providências. Diário Oficial da União. 21 Jun 2014; sec. 1, p. 8-11.

2. Brasil. Ministério da Educação. Conselho Nacional de Educação. Câmara de Educação Superior. Resolução CNE/CES no 4, de 7 de Novembro de 2001. Institui Diretrizes Curriculares Nacionais do Curso de Graduação em Medicina. Diário Oficial da União. 9 Nov 2001; sec. 1, p. 38.

3. Carraccio CL, Englander R. From Flexner to competencies: reflections on a decade and the journey ahead. Acad Med. 2013; 88(8):1067-73.

4. Almeida Filho N. Reconhecer Flexner: inquérito sobre produção de mitos na educação médica no Brasil contemporâneo. Cad Saude Publica. 2010; 26(12):2234-49.

5. Nunes E. Cem anos do relatório Flexner. Cienc Saude Colet. 2010; 15 Supl 1:956.

6. Barreto ICHC, Andrade LOM, Moreira AEMM, Machado MMT, Silva MRF, Oliveira LC, et al. Gestão participativa no SUS e a integração ensino, serviço e comunidade: a experiência da Liga de Saúde da Família, Fortaleza, CE. Saude Soc. 2012; 21 Supl 1:80-93.

7. Gomes LB, Merhy EE. Compreendendo a educação popular em saúde: um estudo na literatura brasileira. Cad Saude Publica. 2011; 27(1):7-18.

8. Teixeira E, Fernandes JD, Andrade AC, Silva KL, Rocha MEMO, Lima RJO. Panorama dos cursos de graduação em enfermagem no Brasil na década das Diretrizes Curriculares Nacionais. Rev Bras Enferm. 2013; 44 Esp:102-10.

9. Freire P. Educação e atualidade Brasileira. 3a ed. São Paulo: Editora Cortez; 2002.

10. Haddad AE, Ristoff D, Passarella TM. A aderência dos cursos de graduação em enfermagem, medicina e odontologia às diretrizes curriculares nacionais. Brasília: Ministério da Saúde; 2006.

11. Katz D, Festinger L, Gomes GJ. A pesquisa na psicologia social. Rio de Janeiro: Fundação Getúlio Vargas; 1974.

12. Duarte R. Entrevistas em pesquisas qualitativas. Educar. 2004; (24):213-25.

13. Stock FS, Sisson MC, Grosseman S. Percepção de estudantes de medicina sobre aprendizagem da relação médico-paciente após mudança curricular. Rev Bras Educ Med. 2012; 36(1):5-13.

14. Backes DS, Colomé JS, Erdmann RH. Grupo focal como técnica de coleta e análise de dados em pesquisas qualitativas. Mundo Saude. 2011; 35(4):438-42.

15. Ludke M, André M. Pesquisa em educação: abordagens qualitativas. São Paulo: E.P.U.; 1986.

16. Alves ZMMB, Silva MHGFD. Análise qualitativa de dados de entrevista: uma proposta. Paidéia. 1992; (2):61-9.

17. Teixeira CFS. A Universidade no século XXI: para uma universidade nova. Cienc Saude Colet. 2013; 18(3):893-7.

18. Almeida-Filho N. Critical technological competence in health. Interface (Botucatu). 2018; 22(66):667-71.

19. Manfredi SM. Trabalho, qualificação e competência profissional - das dimensóes conceituais e políticas. Educ Soc. 2005; 19(64):13-49. 
20. Vleuten CPM, Heeneman S, Schuwirth LWT. Programmatic assessment. In: Dent J, Harden R, Hunt D, organizers. A practical guide for medical teachers. Edinburgh: Elsevier; 2017. p. 295-303.

21. Zeferino A, Passeri S. Avaliação da aprendizagem do estudante. Cad ABEM. 2007; $3: 39-43$

22. Lörwald AC, Lahner FM, Greif R, Berendonk C, Norcini J, Huwendiek S. Factors influencing the educational impact of Mini-CEX and DOPS: a qualitative synthesis. Med Teach. 2018; 40(4):414-20.

23. Daniels VJ, Pugh D. Twelve tips for developing an OSCE that measures what you want. Med Teach. 2018; 40(12):1208-13.

24. Cerqueira JP, Alves SMC. A Constitucionalidade do Projeto Mais Médicos para o Brasil. Cad Ibero Am Direito Sanit. 2016; 5(2):91-107.

25. Couto MP, Salgado ED, Pereira AE. O programa mais médicos: a formulação de uma nova política pública de saúde no brasil. Tempus (Brasília). 2016; 9(4):97.

26. Ferreira NM, Cunha GT, Dias NG. O desafio da mudança: a transformação curricular de um Programa de Residência de Medicina de Família e Comunidade. Rev Bras Med Fam Comunidade. 2018; 13(40):1-12.

27. Brasil. Senado Federal. Constituição da República Federativa do Brasil. Brasília (DF): Senado Federal; 1988.

28. Brasil. Constituição Federal. Constituição Federal (Artigos 196 a 200). Brasília (DF): Senado Federal; 2000.

29. Alves CL, Belisário SA, Abreu DMX, Lemos JMC, D’ávila LS, Goulart LMHF. Curricular transformations in medical school: an exploration of the promotion of change in Brazil. Med Educ. 2013; 47(6):617-26.

30. Slavin SJ, Schindler DL, Chibnall JT. Medical student mental health 3.0: improving student wellness through curricular changes. Acad Med. 2014; 89(4):573-7.

31. Bland CJ, Starnaman S, Wersal L, Moorhead-Rosenberg L, Zonia S, Henry R. Curricular change in medical schools: how to succeed. Acad Med. 2000; 75(6):575-94.

32. Ronzani T. A reforma curricular nos cursos de saúde: qual o papel das crenças? Rev Bras Educ Med. 2007; 31(1):38-43.

33. Bollela V, Germani A, Campos H, Amaral E. Educação baseada na comunidade para as profissões da saúde: aprendendo com a experiência brasileira. Fortaleza: Funpec; 2014.

34. Batista NA, Batista SH, Abdalla IG. Ensino em saúde: visitando conceitos e práticas. São Paulo: Arte \& Ciência; 2005.

35. Campos H, Campos J, Faria M, Barbosa P, Araújo M. Programas de desenvolvimento docente em escolas médicas: oportunidades e perspectivas. Cad ABEM. 2007; 3:34-8.

36. Villegas-Reimers E. Teacher professional development: an international review of the literature. Paris: International Institute for Educational Planning; 2003.

37. Desimone LM. Improving impact studies of teachers' professional development: toward better conceptualizations and measures. Educ Res. 2009; 38(3):181-99.

38. Gozu A, Windish DM, Knight AM, Thomas PA, Kolodner K, Bass EB, et al. Longterm follow-up of a 10-month programme in curriculum development for medical educators: a cohort study. Med Educ. 2008; 42(7):684-92. 
39. Perim GL, Abdalla IG, Aguilar-da-Silva RH, Lampert JB, Stella RCR, Costa NMSC. Desenvolvimento docente e a formação de médicos. Rev Bras Educ Med. 2009; 33 Supl 1:70-82.

40. Finkler M, Caetano JC, Ramos FRS. Integração “ensino-serviço” no processo de mudança na formação profissional em odontologia. Interface (Botucatu). 2011; 15(39):1053-67.

41. Richardson GM, Byrne LL, Liang LL. Making learning visible: developing preservice teachers' pedagogical content knowledge and teaching efficacy beliefs in environmental education. Appl Environ Educ Commun. 2017; 17(1):1-16.

42. Gustin M-P, Abbiati M, Bonvin R, Gerbase MW, Baroffio A. Integrated problembased learning versus lectures: a path analysis modelling of the relationships between educational context and learning approaches. Med Educ. 2018; 23(1):1489690.

43. Dunsmuir S, Frederickson N, Lang J. Meeting current challenges in school psychology training: the role of problem-based learning. School Psych Rev. 2017; 46(4):395-407.

44. Anjos R, Gianini R, Minari F, Luca A, Rodrigues M. "Vivendo o SUS”: uma experiência prática no cenário da atenção básica. Rev Bras Educ Med. 2010; 34(1):172-83.

45. Merhy EE. O desafio que a educação permanente tem em si: a pedagogia da implicação. Interface (Botucatu). 2004; 169(16):172-4.

46. Tempski P. Avaliação da qualidade de vida do estudante de medicina e da influência exercida pela formação acadêmica [tese]. São Paulo: Faculdade de Medicina, Universidade de São Paulo; 2008.

47. Kristina TN, Majoor GD, van der Vleuten CPM. Defining generic objectives for community-based education in undergraduate medical programmes. Med Educ. 2004; 38(5):510-21.

48. Mahoney S, Boileau L, Floridis J, Abi-Abdallah C, Lee B. How social accountability can be incorporated into an urban community-based medical education program: an australian initiative. Educ Health. 2014; 27(2):148-51.

49. Macinko J, Harris MJ. Brazil's Family Health Strategy -- delivering community-based primary care in a universal health system. N Engl J Med. 2015; 372(23):2177-81.

50. Kelly L, Walters L, Rosenthal D. Community-based medical education: is success a result of meaningful personal learning experiences? Educ Health. 2014; 27(1):47-50.

51. Cruz E, Costa FA. Revisitando o(s) sentido (s) para a integração curricular. Rev e-Curric. 2015; 13(2):193-213.

52. Chaves SE. Os movimentos macropolíticos e micropolíticos no ensino de graduação em Enfermagem. Interface (Botucatu). 2014; 18(49):325-36.

53. Franco ECD, Soares AN, Gazzinelli MF. Recontextualização macro e micropolítica do currículo integrado: percursos experimentados em um curso de enfermagem. Esc Anna Nery. 2018; 22(4):e20180053.

54. Abrahão AL, Merhy EE. Formação em saúde e micropolítica: sobre conceitosferramentas na prática de ensinar. Interface (Botucatu). 2014; 18(49):313-24.

55. Ferreira MJM, Ribeiro KG, Almeida MM, Sousa MS, Ribeiro MTAM, Machado MMT, et al. New national curricular guidelines of medical courses: opportunities to resignify education. Interface (Botucatu). 2019; 23 Suppl 1:e170920. 
To understand the National Curriculum Guidelines (NCG) it is necessary to contextualize the reality of each educational institution. The effective implementation of the guidelines requires the (re)orientation of the health education process; promoting integration between the course educational project (CEP); Brazilian National Health System (SUS) and professor engagement. We conducted a qualitative exploratory study using questionnaires to capture professors' perceptions of the alignment between medicine CEPs and the NCG. Content analysis was performed to develop thematic categories. The professors at one school acknowledged that the CEP and NCG were not aligned and their responses revealed that teaching is determined by each professor's professional and personal background. In another school whose curriculum reform adopted active teaching-learning methodologies, the professors felt a sense of ownership in relation to the NCG. We therefore conclude that the CEP change process requires time, dedication and effective communication or, in other words, greater change within the education institution.

Keywords: Medical education. Teaching-service integration. Health planning guidelines.

Comprender la consolidación de las Directrices Curriculares Nacionales demanda poner en contexto la realidad de cada institución. Su implantación presupone una (re)orientación del proceso de formación en la salud, con integración entre Proyecto Pedagógico del Curso, Sistema Brasileño de Salud (SUS) y envolvimiento docente. Para captar la percepción docente sobre el alineamiento entre PPC y DCN, se realizó un estudio exploratorio, con metodología cualitativa, en el que los docentes respondieron a un cuestionario. Se utilizó un análisis de contenido para la construcción de categorías temáticas. Los docentes de una escuela reconocen que el PPC no está alineado a las DCN. Revelan un trabajo docente determinado por perfil profesional y personal. En otra escuela, cuya reforma curricular ya adopta la metodología de enseñanza-aprendizaje activa, los docentes se sienten apropiados de las DCN. Concluimos, por lo tanto, que los cambios en los PPC son procesos que demandan tiempo, dedicación y comunicación, es decir, un mayor cambio en la institución de enseñanza.

Palabras clave: Educación médica. Integración enseñanza-servicio. Directrices para la planificación en salud. 